\title{
Estado nutricional e frações foliares de P no cafeeiro em função da adubação fosfatada
}

\author{
Thiago Henrique Pereira Reis ${ }^{(1)}$, Antônio Eduardo Furtini Neto(1), Paulo Tácito Gontijo Guimarães(2), \\ Antônio Fernando Guerra ${ }^{(3)}$ e César Henrique Caputo de Oliveira(1)
}

\begin{abstract}
(1)Universidade Federal de Lavras (Ufla), Departamento de Ciência do Solo, Caixa Postal 3.037, CEP $37200-000$ Lavras, MG. E-mail: thiagohpreis@yahoo.com.br, afurtini@dcs.ufla.br, cesar_caputo@yahoo.com.br ${ }^{(2)}$ Empresa de Pesquisa Agropecuária de Minas Gerais, Campus da Ufla, Caixa Postal 176, CEP 37200-000 Lavras, MG. E-mail: paulotgg@epamig.ufla.br ${ }^{(3)}$ Embrapa Cerrados, Caixa Postal 08223, Rodovia BR-020, Km 18, CEP 73310-970 Planaltina, DF. E-mail: guerra@cpac.embrapa.br
\end{abstract}

Resumo - O objetivo deste trabalho foi avaliar, nas épocas seca e chuvosa, o estado nutricional e as frações foliares de $\mathrm{P}$ no cafeeiro, em resposta à adubação fosfatada, e determinar relação destas com a produtividade da cultura. Utilizou-se a cultivar Rubi MG-1192, sob pivô central, em plantio adensado (7.143 plantas ha ${ }^{-1}$ ) sobre Latossolo Vermelho, na região dos Cerrados. Entre 2002 e 2010, foram utilizadas as doses anuais de 0, 50, 100,200 e $400 \mathrm{~kg} \mathrm{ha}^{-1}$ de $\mathrm{P}_{2} \mathrm{O}_{5}$. As amostras foliares foram retiradas após a colheita, em julho (época seca), e antes da fase de enchimento de grãos, em dezembro (época chuvosa). Os teores de $\mathrm{P}$ foliar foram avaliados em 2009 e 2010, e a produção, de 2008 a 2011. A produtividade do cafeeiro respondeu linearmente a doses de até $400 \mathrm{~kg} \mathrm{ha}^{-1}$ de $\mathrm{P}_{2} \mathrm{O}_{5}$. Em condições de alta produtividade, com alto suprimento de $\mathrm{P}$, as faixas de suficiência do nutriente possivelmente são maiores que as relatadas na literatura. A reserva de fósforo inorgânico nas folhas do cafeeiro aumenta em plantas com melhor suprimento de $\mathrm{P}$, o que garante maior atividade metabólica das plantas em períodos de estresse hídrico e possibilita maior produtividade.

Termos para indexação: Coffea arabica, cafeeiro irrigado, estresse hídrico, fósforo inorgânico, fósforo orgânico, plantio adensado.

\section{Nutritional status and foliar fractions of $P$ in coffee plants according to phosphate fertilization}

\begin{abstract}
The objective of this work was to evaluate, in the rainy and dry seasons, the nutritional status and foliar fractions of $\mathrm{P}$ in coffee plants, according to phosphate fertilization, and to determine their relation with coffee yield. The cultivar Rubi MG-1192 of Arabic coffee was used under central-pivot, with high density (7,143 plants per ha) on Rhodic Hapludox, in the Cerrados' region. From 2002 to 2010, the following annual doses of P were used: $0,50,100,200$, and $400 \mathrm{~kg} \mathrm{ha}^{-1} \mathrm{P}_{2} \mathrm{O}_{5}$. Foliar samples were taken after harvest, in July (dry season), and before grain filling stage, in December (rainy season). Foliar P contents were evaluated in 2009 and 2010, and the coffee yield, from 2008 to 2011. Coffee yield responded linearly to doses up to $400 \mathrm{~kg} \mathrm{ha}^{-1}$ of $\mathrm{P}_{2} \mathrm{O}_{5}$. In high yielding conditions, with high $\mathrm{P}$ supply, foliar ranges of $\mathrm{P}$ are probably different from the ones reported in literature. The reserve of inorganic phosphorus in coffee leaves increases in plants with improved $\mathrm{P}$ supply, which ensures greater metabolic activity of plants during periods of drought stress and enables higher productivity.
\end{abstract}

Index terms: Coffea arabica, irrigated coffee, hydric stress, inorganic phosphorus, organic phosphorus, high density planting.

\section{Introdução}

As espécies vegetais respondem diferentemente à disponibilidade de P no solo (Bhadoria et al., 2004), e possuem vários mecanismos bioquímicos e fisiológicos para aumentar a eficiência de absorção e utilização deste elemento (Raghothama \& Karthikeyan, 2005; Rouached et al., 2010). As plantas acumulam P principalmente em duas formas: a $\mathrm{P}$ inorgânica (Pi), armazenada no vacúolo e responsável pela fração não metabólica de P na planta; e a P orgânica (Po), que é a fração metabólica por meio da qual a planta utiliza o nutriente presente no citoplasma de suas células (Novais \& Smith, 1999). A maior eficiência no uso do nutriente pelas plantas está associada à capacidade destas em realizar a ciclagem interna do $\mathrm{Pi}$, movendo-o da fração não metabólica para a fração metabólica em momentos de estresse ou quando há maior demanda pelo nutriente (Wang et al., 2010).

A resposta das plantas à adubação fosfatada varia de acordo com a dinâmica das frações de P nas células, 
avaliada por meio dos teores de Pi e Po nas folhas (Fernandes et al., 2000; Martinez et al., 2005; Santos et al., 2008). O tamanho do estoque de $P$ na fração não metabólica e a habilidade das plantas em utilizar essa reserva contribuem para sua adaptação a condições de estresse nutricional (Malavolta et al., 2002; Akhatr et al., 2008). No entanto, a maioria dos estudos sobre a dinâmica das frações fosfatadas na planta foi realizada em condições controladas, para avaliar diferentes cultivares e suas respostas ao estresse nutricional de P (Fernandes et al., 2000; Martinez et a., 2005; Santos et al., 2008).

$\mathrm{O}$ cafeeiro em produção necessita de maior suprimento de $\mathrm{P}$, uma vez que a planta demanda mais energia para suprir o dreno dos frutos e para desenvolver sua parte vegetativa (Laviola et al., 2007a), a qual será responsável pela produção do ano seguinte. Além disso, a cultura responde bem à aplicação do nutriente em sistemas com alta produtividade (Guerra et al., 2007; Reis et al., 2011; Dias, 2012). Portanto, é importante que se verifique, em campo e em diferentes épocas, como os cafeeiros utilizam o P após a absorção do nutriente e qual a fração do nutriente está mais estreitamente associada a maiores produtividades da cultura.

O objetivo deste trabalho foi avaliar, nas épocas seca e chuvosa, o estado nutricional e as frações foliares de $\mathrm{P}$ no cafeeiro, em resposta à adubação fosfatada, e determinar relação destas com a produtividade da cultura.

\section{Material e Métodos}

A cultura do cafeeiro foi instalada em janeiro de 2001, em Latossolo Vermelho Distrófico típico (LVd) com textura muito argilosa, no Município de Planaltina, DF, na Embrapa Cerrados (153' $42^{\prime \prime} S$ e 47 $43^{\prime} 51^{\prime \prime} W$ ), à altitude de $1.009 \mathrm{~m}$. Segundo a classificação de Köppen, o clima do local é do tipo Aw, tropical chuvoso, com inverno seco e temperatura média anual de $23^{\circ} \mathrm{C}$. O período de seca varia de 5 a 6 meses (abril a setembro), e a precipitação média anual é de $1.400 \mathrm{~mm}$, concentrada de outubro a março.

Foi utilizada a cultivar Rubi MG-1192, de cafeeiro arábica, no espaçamento $2,8 \times 0,5 \mathrm{~m}$, implantada conforme as recomendações de Ribeiro et al. (1999). A partir da primeira florada, em 2002, iniciou-se a aplicação anual de diferentes doses de $\mathrm{P}(0,50,100$, 200 e $400 \mathrm{~kg} \mathrm{ha}^{-1}$ de $\mathrm{P}_{2} \mathrm{O}_{5}$ ), na projeção da copa dos cafeeiros, tendo-se utilizado como fonte o superfosfato triplo. As aplicações foram feitas seguindo o esquema: $2 / 3$ da dose em setembro, antes do retorno das irrigações e após período de estresse hídrico, e 1/3 entre o final de dezembro e início de janeiro. Para os demais nutrientes, foi realizada aplicação anual de $500 \mathrm{~kg} \mathrm{ha}^{-1}$ de $\mathrm{N}$, na forma de ureia, e $500 \mathrm{~kg} \mathrm{ha}^{-1}$ de $_{2} \mathrm{O}$, na forma de cloreto de potássio; e, a cada dois anos, a aplicação de $100 \mathrm{~kg} \mathrm{ha}^{-1}$ do fertilizante FTE BR10 (Zn, 7\%; B, 2,5\%; Cu, 1\%; Fe, 4\%; Mn, 4\%; Mo, 0,1\%; Co, 0,1\%), para suprimento de micronutrientes. As aplicações de $\mathrm{N}$ e $\mathrm{K}$ foram parceladas de setembro a fevereiro, em quatro aplicações. $\mathrm{O}$ tratamento fitossanitário foi $\mathrm{o}$ mesmo, para todas as parcelas, e realizado sempre que necessário.

Utilizou-se o delineamento experimental de blocos ao acaso, com três repetições, em que as parcelas consistiram de três linhas de plantio com dez plantas em cada linha, com as oito plantas centrais da linha do meio consideradas a parcela útil. A área foi irrigada por pivô central, em regime de estresse hídrico moderado (Guerra et al., 2006), para sincronização do desenvolvimento de gemas reprodutivas e uniformização da florada.

Nos anos de 2009 e 2010, foram coletadas amostras compostas de 50 pares de folhas do terço médio das plantas, no terceiro ou quarto par de folhas do ramo plagiotrópico. As amostras foram retiradas após a colheita em julho e, também, antes da fase de enchimento de grãos, em dezembro. A produção das parcelas foi avaliada nos anos de 2008 a 2011. A colheita foi feita por meio de derriça manual sobre "pano".

Parte das folhas frescas coletadas foi pesada e imediatamente congelada em ácido perclórico, a $0,2 \mathrm{~mol} \mathrm{~L}^{-1} \mathrm{HClO}_{4}$, para realização do fracionamento das formas de fósforo na matéria fresca da planta (Martinez et al., 2005). Foram determinados os teores de $\mathrm{P}$ inorgânico solúvel em ácido $(\mathrm{Pi})$, presente no vacúolo das células como compartimento de reserva, e P total solúvel em ácido (Pts). Por diferença entre as frações, determinou-se o P orgânico solúvel em ácido (Po), forma de $\mathrm{P}$ metabolicamente ativa nas células da planta. As demais folhas foram secas a $60^{\circ} \mathrm{C}$, em estufa de circulação forçada de ar, até obtenção de massa constante. Em seguida, as amostras foram moídas e, após digestão nítrico-perclórica, foi determinado $\mathrm{o}$ teor de $\mathrm{P}$ na matéria seca das folhas (Malavolta 
et al., 1997). Os teores de $\mathrm{P}$ foram determinados por espectroscopia de absorção molecular (colorimetria), em todos os extratos, por meio da redução do complexo fosfomolibdato por ácido ascórbico.

Os dados obtidos foram submetidos à análise de variância e testes de média (Skott-Knott, a 5\% de probabilidade). As equações de regressão foram ajustadas para os teores de P na matéria seca das folhas, e para as diferentes frações de $\mathrm{P}$ na matéria fresca das folhas, como variáveis dependentes das doses de $\mathrm{P}_{2} \mathrm{O}_{5}$ aplicadas ao solo. Todas as análises foram realizadas com o programa Sisvar (Ufla, Lavras).

\section{Resultados e Discussão}

$\mathrm{O}$ cafeeiro respondeu às doses de $\mathrm{P}$, em todos os anos avaliados (Figura 1). Houve ajuste linear significativo

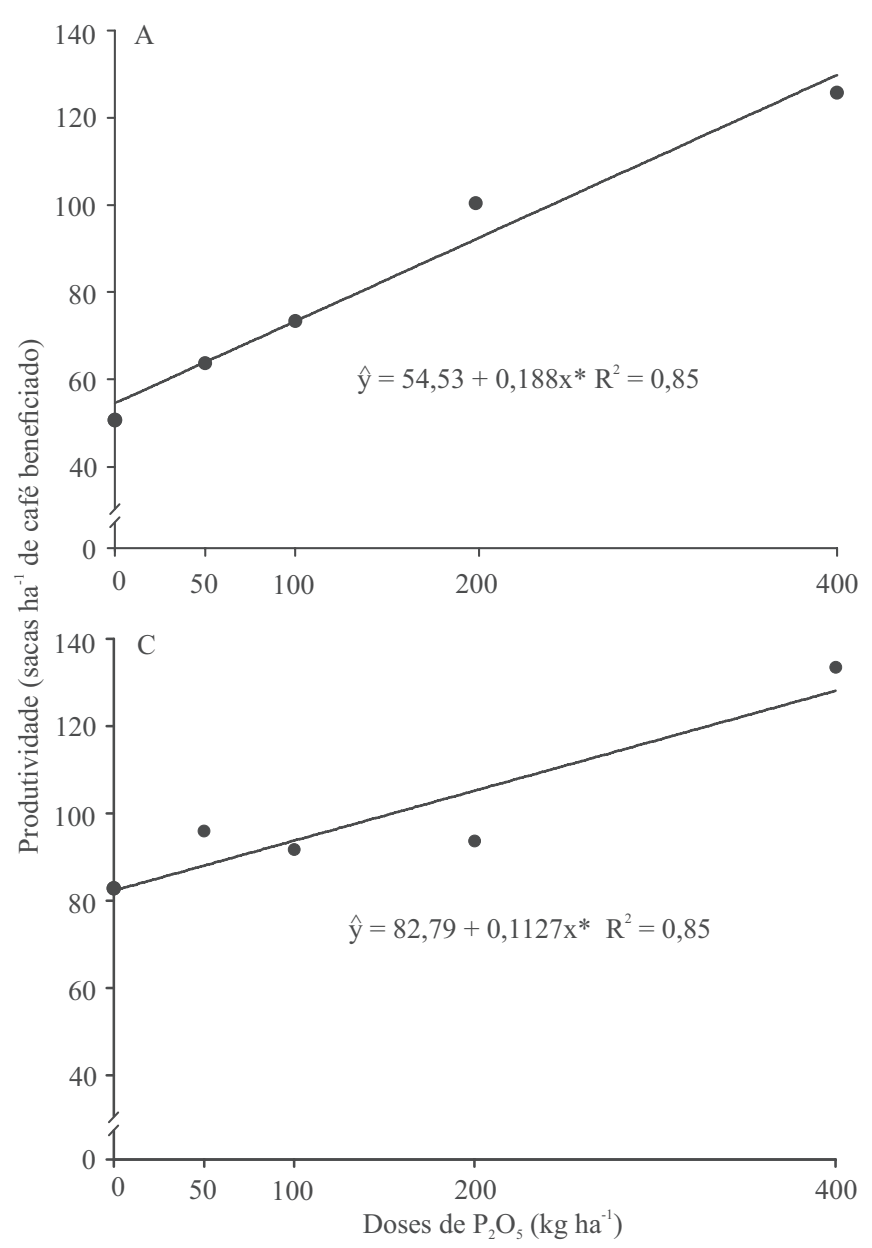

nos anos de safra alta (2008 e 2010) e de baixa (2009). A média geral após oito anos de cultivo também ajustou-se linearmente às doses de P. Resultados semelhantes foram relatados por Guimarães (1986), Melo et al. (2005) e Dias (2012).

$\mathrm{Na}$ safra de 2008, ano de alta produtividade, a resposta das plantas à adubação fosfatada foi mais expressiva, conforme indicado pelo maior coeficiente angular da equação ajustada (Figura 1 A). No entanto, em 2010, outro ano de alta, apesar de a regressão ter apresentado um coeficiente angular relativamente elevado, observou-se que apenas a dose de $400 \mathrm{~kg} \mathrm{ha}^{-1}$ de $\mathrm{P}_{2} \mathrm{O}_{5}$ teve efeito pronunciado sobre a produtividade (Figura 1 C). Em 2009, ano de baixa, as produtividades ainda foram elevadas, nos tratamentos com as maiores
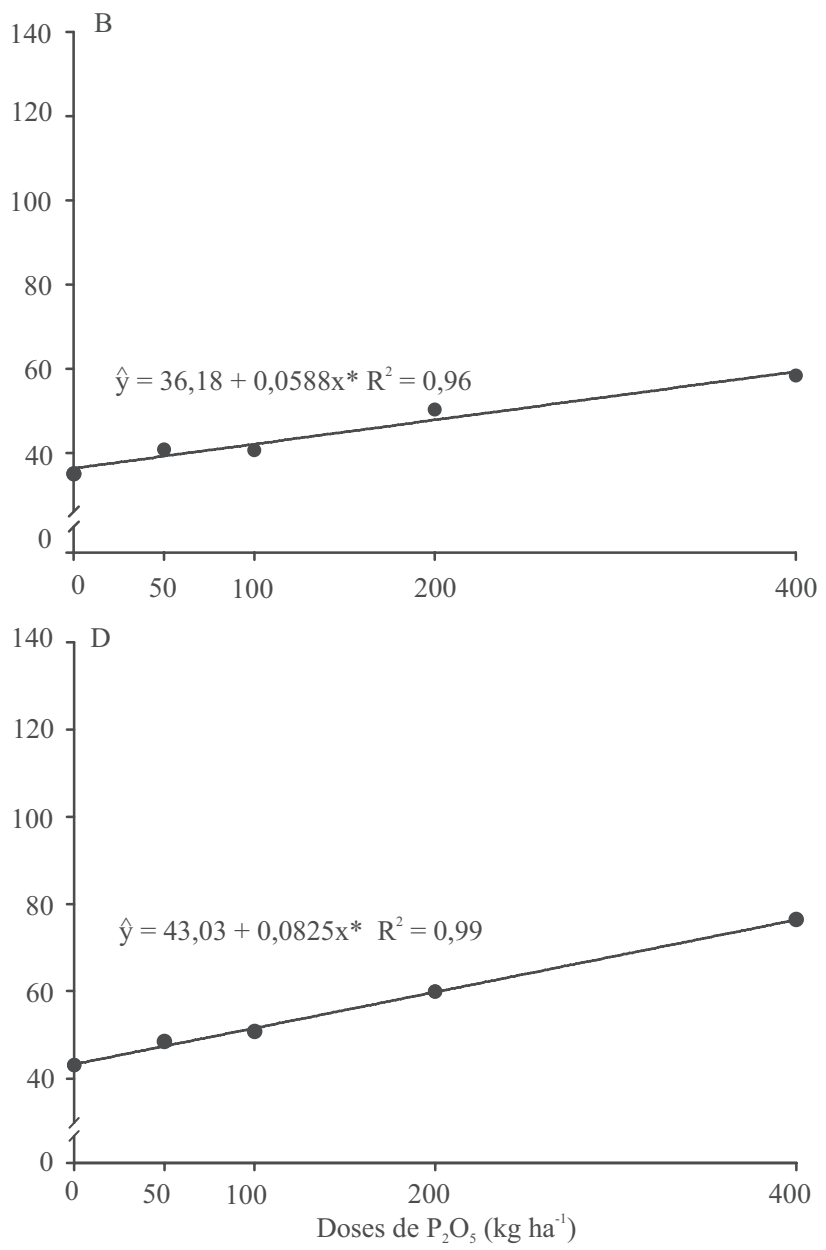

Figura 1. Produtividade da cultivar Rubi MG-1192 de cafeeiro, em função da aplicação anual de diferentes doses de $\mathrm{P}_{2} \mathrm{O}_{5}$. A, safras de 2008; B, de 2009; C, de 2010; e D, média geral do ensaio após oito anos de cultivo. *Significativo, pelo teste t, a $5 \%$ de probabilidade. 
doses de $\mathrm{P}$, de 47,9 e 59,7 sacas ha ${ }^{-1}$, respectivamente (Figura $1 \mathrm{~B}$ ).

Estes dados mostram claramente a bienalidade da cultura e que, no ano de safra baixa (Figura $1 \mathrm{~B}$ ), o efeito da bienalidade é amenizado nas plantas com maior suprimento de P. Para a média geral dos anos do ensaio (Figura 1 D), a produtividade variou de 43,0 a 76,0 sacas ha ${ }^{-1}$ de café beneficiado, entre a testemunha e a maior dose de P. Isso corresponde a um incremento médio de $76,7 \%$ na produtividade, mesmo com a inclusão do ano de 2006, quando não houve produção em razão da poda praticada. Estes resultados confrontam as atuais recomendações para a adubação fosfatada do cafeeiro e as expectativas de produtividade da cultura (Raij et al., 1997; Ribeiro et al., 1999).

Guerra et al. (2007) e Reis et al. (2011), no mesmo ensaio, em anos anteriores, já apontavam esse incremento expressivo de produtividade em consequências das maiores doses de P. Outros trabalhos relataram incrementos menores na produtividade, de 12 a $16 \%$, com doses de 0 a $180 \mathrm{~kg} \mathrm{ha}^{-1}$ de $\mathrm{P}_{2} \mathrm{O}_{5}$ (Gallo et al., 1999; Prezotti \& Rocha, 2004). Contudo, a cultivar Rubi MG-1192 é considerada responsiva ao aumento na fertilidade do solo (Amaral et al., 2010), e o espaçamento adensado utilizado, com 7.143 plantas ha ${ }^{-1}$, também contribuiu para as maiores produtividades observadas neste ensaio. A produtividade média da testemunha foi de 43,0 sacas ha $^{-1}$, que é considerada alta comparativamente à média brasileira $\left(\approx 20,0\right.$ sacas ha $\left.^{-1}\right)$ (Companhia Nacional de Abastecimento, 2012). Além disso, deve-se levar em consideração a elevada adubação fosfatada realizada no sulco de plantio, na instalação do ensaio (Ribeiro et al., 1999), e a estreita relação entre a disponibilidade de água e a absorção de P (Novais \& Smyth, 1999). Esses dados contribuem para explicar as elevadas produtividades observadas mesmo no tratamento testemunha.

$\mathrm{Na}$ análise da viabilidade econômica da adubação anual com maiores doses de $\mathrm{P}_{2} \mathrm{O}_{5}$, considerouse a equação que refletiu os resultados de sete safras colhidas em oito anos de experimento (Figura 1 D). Para cada $50 \mathrm{~kg}$ de $\mathrm{P}_{2} \mathrm{O}_{5}$ aplicados anualmente, obteve-se $\mathrm{o}$ retorno bruto de 4,25 sacas $^{-1} \mathrm{a}^{-1}$ de café beneficiado. A fonte utilizada foi o superfosfato triplo, com $46 \%$ de $\mathrm{P}_{2} \mathrm{O}_{5}$, a preço de mercado $(28 / 2 / 2012)$ de $\mathrm{R} \$ 1.100,00$ (US\$ 647,00) por tonelada. Nessa mesma data, o preço da saca de café beneficiado tipo seis, 'Bica Corrida', foi de $\mathrm{R} \$ 435,00$ (US\$ 256,00), com o dólar a R\$1,70. Nesta situação, para cada $\mathrm{R} \$ 120,00$ (US\$ 70,00), investidos na aplicação do fertilizante fosfatado, por hectare, o cafeicultor teria um retorno financeiro bruto de $\mathrm{R} \$ 1.850,00$ (US\$ $1.088,00$ ) por hectare.

As doses de $\mathrm{P}_{2} \mathrm{O}_{5}$ influenciaram significativamente os teores foliares de $\mathrm{P}$, em todas as épocas de avaliação (Figura 2). Em julho de 2009, no período após a colheita de uma safra de baixa, os teores foliares de $\mathrm{P}$ ajustaram-se linearmente às doses de $\mathrm{P}$ (Figura 2 A). Assim, é possível que as plantas mais bem supridas com $\mathrm{P}$ conseguiriam atender de forma mais adequada às demandas energéticas e nutricionais da futura florada (Malavolta et al., 2002; Taiz \& Zeiger, 2009; Silva et al., 2010). Em 2010, após a colheita de uma safra de alta, apesar da ausência de ajuste, os tratamentos apresentaram maiores teores que a testemunha (Figura $2 \mathrm{C}$ ). Os teores de $\mathrm{P}$, nesta época em 2010, foram, em geral, maiores que no ano anterior.

Quanto aos teores de P nas amostras coletadas em dezembro, na fase anterior ao enchimento de grãos, observou-se ajuste exponencial dos teores foliares de $\mathrm{P}$ às doses de $\mathrm{P}_{2} \mathrm{O}_{5}$ aplicadas, em ambos os anos (Figuras 2 B e D), semelhantemente ao ocorrido nas amostras de 2007 (Reis et al., 2011). Porém, no período avaliado por Reis et al. (2011), os teores foliares de $\mathrm{P}$ estabilizaram-se em $1,98 \mathrm{~g} \mathrm{~kg}^{-1}$, à dose de $270 \mathrm{~kg} \mathrm{ha}^{-1}$ de $\mathrm{P}_{2} \mathrm{O}_{5}$. Já nos dois períodos avaliados no presente estudo, os teores foliares estabilizaram-se em 2,31 e 2,20 $\mathrm{g} \mathrm{kg}^{-1}$, às doses 240 e $60 \mathrm{~kg} \mathrm{ha}^{-1}$ de $\mathrm{P}_{2} \mathrm{O}_{5}$, respectivamente para 2009 e 2010.

Os maiores teores foliares de $\mathrm{P}$, em cafeeiro, geralmente são observados em amostragens realizadas antes do enchimento de grãos (Valarini et al., 2005; Laviola et al., 2007b). Após essa fase, os frutos entram no chamado estádio de desenvolvimento ou de expansão rápida, quando ocorre a maior translocação de fotoassimilados para os frutos de cafeeiro, o que acaba por diluir os teores foliares de P (Laviola et al., 2007a, 2009).

As faixas de suficiência de teores de $\mathrm{P}$, em folhas coletadas no período anterior ao enchimento de grãos, são utilizadas para averiguar o suprimento ideal do nutriente na planta (Martinez et al., 2004; Valarini et al., 2005). No presente trabalho, apenas os teores foliares de $\mathrm{P}$ obtidos na testemunha, estiveram dentro 
dos valores recomendados para a faixa de suficiência do cafeeiro, de 1,2 a 2,0 $\mathrm{g} \mathrm{kg}^{-1}$. Os demais tratamentos apresentaram teores acima do limite superior da faixa. Assim, para um monitoramento nutricional adequado, é importante que também se avalie a cultura em campo, pois deve-se considerar o desenvolvimento vegetativo das plantas e a expectativa de colheita.

As frações fosfatadas foram afetadas significativamente pelos tratamentos, na maioria das épocas de coleta (Figuras 3, 4, 5 e 6). Os teores de Pi foram menores na testemunha, em todos os períodos, com ajuste significativo apenas para a coleta em julho. O Pi é considerado uma forma de reserva do nutriente, que fica armazenada no vacúolo e é utilizada para manter constantes os níveis de $\mathrm{P}$ metabolizável no citoplasma (Raghothama \& Karthikeyan, 2005; Wang et al., 2010). O compartimento Pi é extremamente lábil (Ostertag, 2010), logo essa fração torna-se mais importante em momentos de estresse nutricional de $\mathrm{P}$,
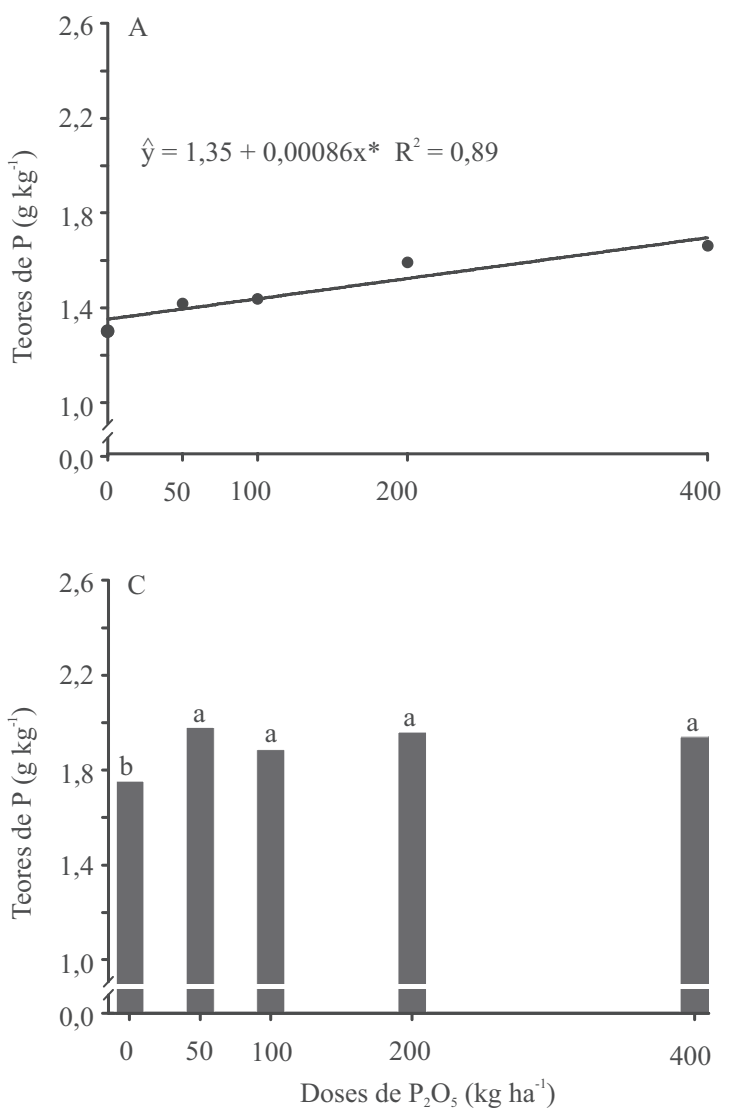

Figura 2. Teores foliares de fósforo em cafeeiro submetido à aplicação anual de diferentes doses de $\mathrm{P}_{2} \mathrm{O}_{5}$. $\mathrm{A}$, amostras retiradas após a colheita, em julho 2009 (seca); B, amostras retiradas antes do enchimento de grãos, em dezembro de 2009 (período chuvoso); C, em julho 2010; e D, em dezembro de 2010. *Significativo, pelo teste t, a 5\% de probabilidade. Médias seguidas de letras iguais não diferem pelo teste de Scott-Knott, a 5\% de probabilidade. em razão do baixo suprimento ou da baixa umidade no solo (Akhatr et al., 2008). Portanto, a coleta em julho é fundamental para que se compreenda a dinâmica das frações fosfatadas no cafeeiro, uma vez que não há irrigação da cultura nesse período, e a planta vai demandar bastante energia para atravessar o período seco e preparar-se para a nova florada (Malavolta et al., 2002; Silva et al., 2010).

Os tratamentos que conseguiram suprir melhor as plantas em $\mathrm{Pi}$, nessa época, independentemente do ano (Figuras 3 A e $5 \mathrm{~A}$ ), foram aqueles que, em geral, possibilitaram um maior desenvolvimento vegetativo das plantas, um melhor "pegamento" da florada e, consequentemente, uma maior produtividade, pois atenderam adequadamente à demanda nutricional desse período (Malavolta et al., 2002). Em julho de 2010, após uma safra alta, as plantas que receberam maior dose do $\mathrm{P}$ parecem ter utilizado mais de sua reserva de $\mathrm{Pi}$, para obter maior produtividade do que as
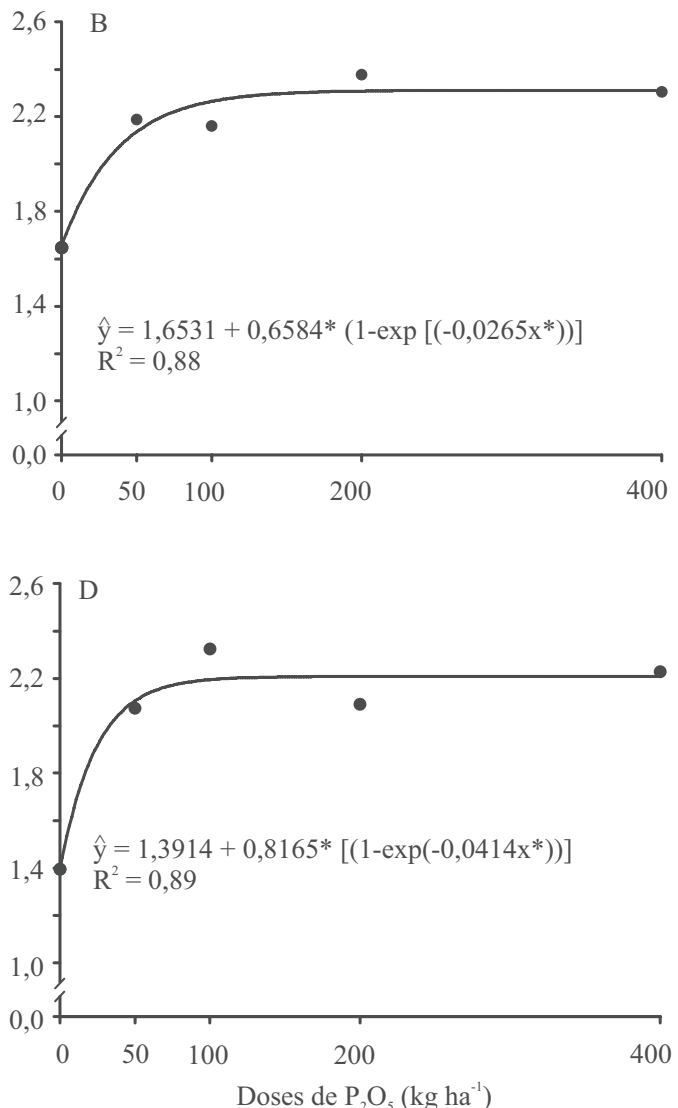

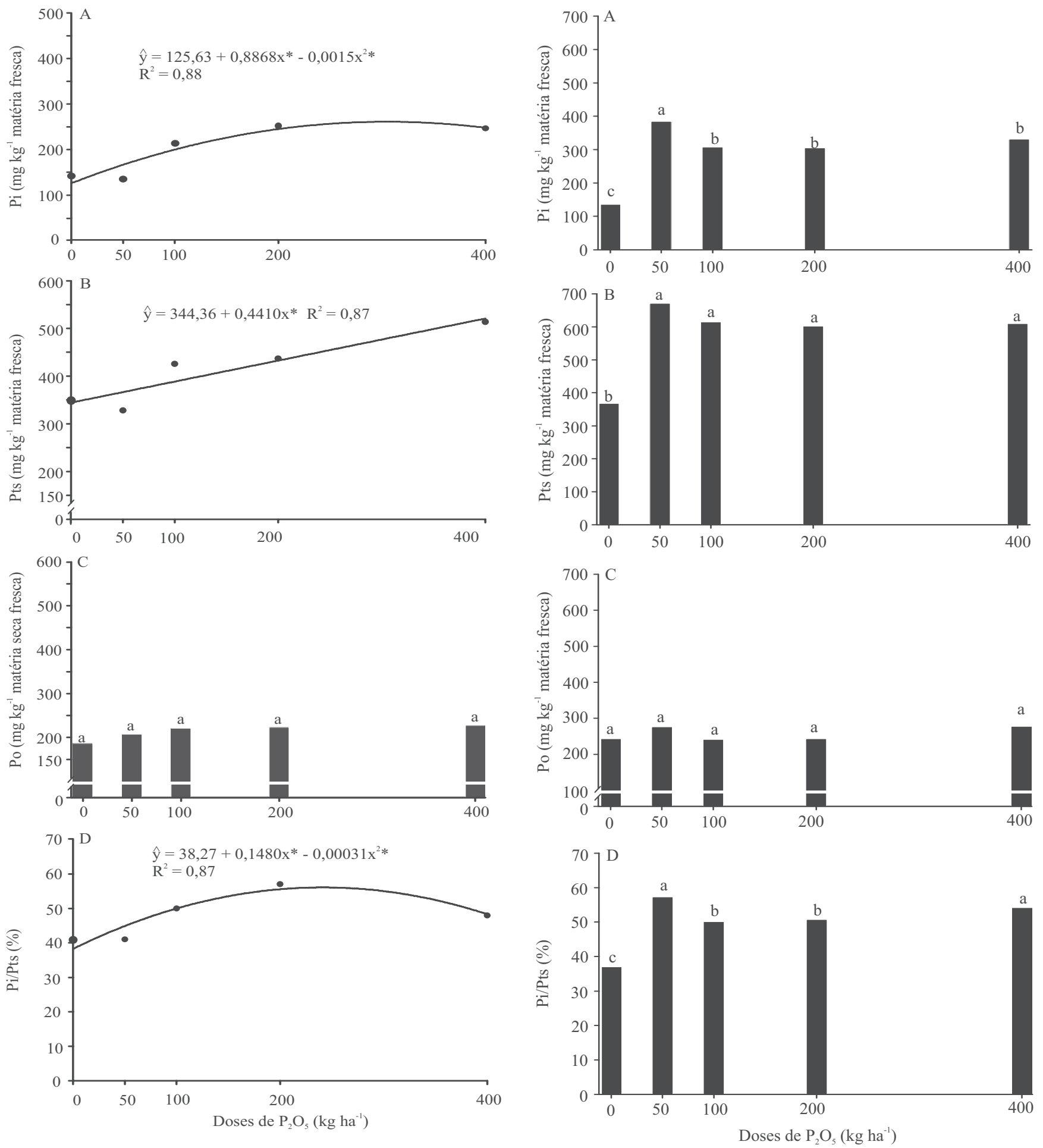

Figura 3. Frações fosfatadas em folhas de cafeeiro, submetido à aplicação anual de diferentes doses de $\mathrm{P}_{2} \mathrm{O}_{5}$, em amostras coletadas em julho de 2009. A, teores de P inorgânico (Pi); B, fósforo total solúvel (Pts); C, fósforo orgânico (Po); e D, relação Pi/Pts. *Significativo pelo teste t, a 5\% de probabilidade. Médias seguidas de letras iguais não diferem pelo teste de Scott-Knott, a $5 \%$ de probabilidade.

Figura 4. Frações fosfatadas em folhas de cafeeiro, submetido à aplicação anual de diferentes doses de $\mathrm{P}_{2} \mathrm{O}_{5}$, em amostras coletadas em dezembro de 2009. A, teores de $\mathrm{P}$ inorgânico (Pi); B, fósforo total solúvel (Pts); C, fósforo orgânico (Po); e D, relação Pi/Pts. *Significativo pelo teste t, a $5 \%$ de probabilidade. Médias seguidas de letras iguais não diferem pelo teste de Scott-Knott, a 5\% de probabilidade. 

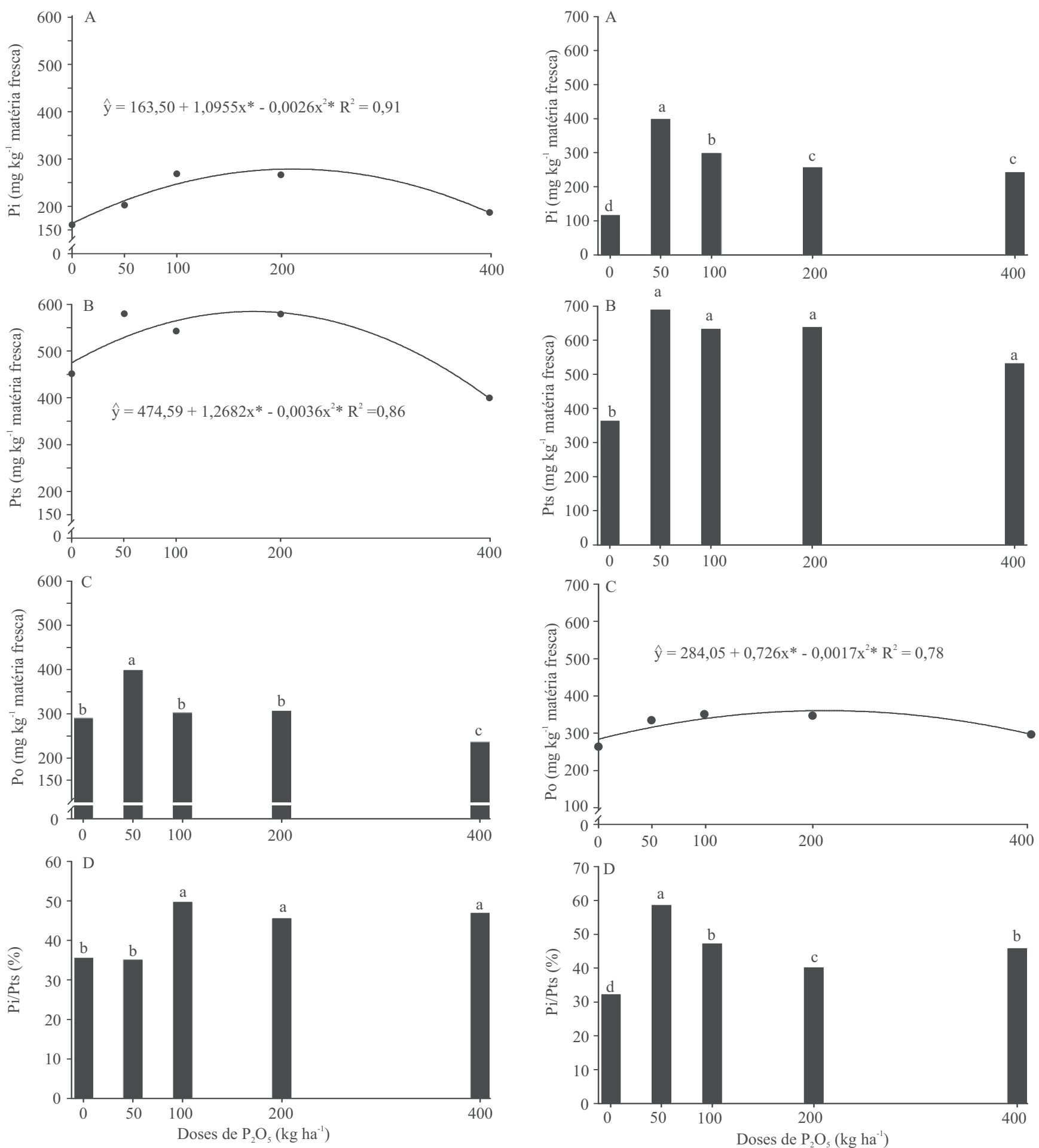

Figura 5. Frações fosfatadas em folhas de cafeeiro, submetido à aplicação anual de diferentes doses de $\mathrm{P}_{2} \mathrm{O}_{5}$, em amostras coletadas em julho de 2010. A, teores de $\mathrm{P}$ inorgânico (Pi); B, fósforo total solúvel (Pts); C, fósforo orgânico (Po); e D, relação Pi/Pts. *Significativo pelo teste t, a $5 \%$ de probabilidade. Médias seguidas de letras iguais não diferem pelo teste de Scott-Knott, a 5\% de probabilidade.

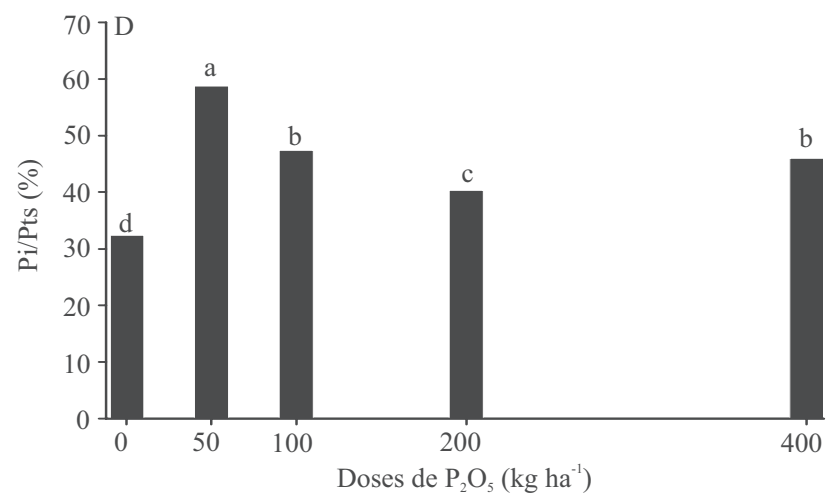

Figura 6. Frações fosfatadas em folhas de cafeeiro, submetido à aplicação anual de diferentes doses de $\mathrm{P}_{2} \mathrm{O}_{5}$, em amostras coletadas em dezembro de 2010. A, teores de P inorgânico (Pi); B, fósforo total solúvel (Pts); C, fósforo orgânico (Po); e D, relação Pi/Pts. *Significativo pelo teste t, a $5 \%$ de probabilidade. Médias seguidas de letras iguais não diferem pelo teste de Scott-Knott, a 5\% de probabilidade. 
demais (Figura $1 \mathrm{C}$ ), pois houve expressiva diminuição dessa fração (Figura $5 \mathrm{~A}$ ).

Como a maior parte da adubação fosfatada ocorre no mês de setembro, os resultados para a amostragem de dezembro mostram que plantas mais bem supridas com o nutriente também têm maior capacidade de absorver P para armazenamento (Novais \& Smyth, 1999; Fernandes et al., 2000; Santos et al., 2008), já que, nessa época, todos os tratamentos superaram a testemunha (Figuras 4 A e 6 A). O maior teor de Pi foi observado nas plantas que receberam apenas $50 \mathrm{~kg} \mathrm{ha}^{-1}$ de $\mathrm{P}_{2} \mathrm{O}_{5}$. Esse resultado deveu-se, possivelmente, a uma menor mobilização do Pi armazenado, uma vez que as plantas deste tratamento provavelmente apresentaram uma menor demanda pelo nutriente, já que obtiveram menor produtividade.

Em geral, os teores de fósforo total solúvel (Pts) aumentaram à medida que as doses de $\mathrm{P}$ aplicadas ao solo aumentaram, exceto no tratamento com a maior dose na amostragem de julho de 2010, que apresentou os menores valores, possivelmente em razão de uma exportação elevada de $\mathrm{P}$ após essa safra expressiva (Figura 5 B). Os ajustes matemáticos foram possíveis apenas nesse período de amostragem (Figuras 3 B, 5 B). O incremento em Pts normalmente acompanha o de $\mathrm{Pi}$, uma vez que os teores de $\mathrm{P}$ orgânico mantêm-se relativamente semelhantes nos tratamentos, independentemente do período avaliado (Figuras $3 \mathrm{C}$, 4 C, 5 C e 6 C). No entanto, na coleta de julho de 2010 , após uma das maiores safras do ensaio, observou-se uma diminuição significativa de Po, na maior dose de $\mathrm{P}$ utilizada. A relativa estabilidade nos teores de Po era esperada, uma vez que o Pi é para tamponar seus teores, o que garantiria maior estabilidade aos processos metabólicos da planta (Martinez et al., 2005).

As maiores relações $\mathrm{Pi} / \mathrm{Pts}$ e $\mathrm{Pi} / \mathrm{Po}$ foram obtidas com as maiores doses de P, na amostragem de julho. Essas maiores relações estiveram, portanto, associadas a maiores produtividades. Em períodos de estresse nutricional, pela diminuição da umidade do solo, as plantas utilizam o Pi armazenado para garantir sua atividade metabólica (Akhatr et al., 2008), o que possibilitaria o atendimento da demanda energética para a florada e para o desenvolvimento vegetativo do cafeeiro (Malavolta et al., 2002; Silva et al., 2010). Assim, plantas mais bem supridas de $\mathrm{P}$, em períodos críticos do ciclo da cultura, devem alcançar maiores produtividades.

\section{Conclusões}

1. Em condições irrigadas e de plantio adensado, o cafeeiro responde de forma econômica a adubações fosfatadas muito elevadas, de até $400 \mathrm{~kg} \mathrm{ha}^{-1}$ de $\mathrm{P}_{2} \mathrm{O}_{5}$.

2. Em condições de alta produtividade e de alto suprimento de $\mathrm{P}$, as faixas de suficiência desse nutriente são ampliadas.

3. A reserva de P inorgânico nas folhas do cafeeiro aumenta em plantas com maior suprimento de $\mathrm{P}$, o que garante maior atividade metabólica das plantas em períodos de estresse hídrico e possibilita maior produtividade do cafeeiro.

\section{Agradecimentos}

Ao Conselho Nacional de Desenvolvimento Científico e Tecnológico (CNPq), à Fundação de Amparo à Pesquisa do Estado de Minas Gerais (Fapemig) e ao Instituto Nacional de Ciência e Tecnologia do Café (INCT-Café), pela concessão de bolsas e apoio financeiro.

\section{Referências}

AKHATR, M.S.; OKI, Y.; ADACHI, T. Intraspecific variations of phosphorus absorption and remobilization, $\mathrm{P}$ forms, and their internal buffering in Brassica cultivars exposed to a P-stressed environment. Journal of Integrative Plant Biology, v.50, p.703-716, 2008. DOI: 10.1111/j.1744-7909.2008.00675.x.

AMARAL, J.F.T. do; MARTINEZ, H.E.P.; LAVIOLA, B.G.; FERNANDES FILHO, E.I.; CRUZ, C.D. Eficiência na produção de frutos e alocação relativa de nutrientes em cultivares de cafeeiro. Revista Ceres, v.57, p.253-262, 2010. DOI: 10.1590/ S0034-737X2010000200018.

BHADORIA, P.S.; EL DESSOUGI, H.; LIEBERSBACH, H.; CLAASSEN, N. Phosphorus uptake kinetics, size of root system and growth of maize and groundnut in solution culture. Plant and Soil, v.262, p.327-336, 2004. DOI: 10.1023/B:PL SO.0000037051.16411.03.

COMPANHIA NACIONAL DE ABASTECIMENTO. Histórico de produção de café. Disponível em: <http://www.conab. gov.br/OlalaCMS/uploads/arquivos/13_09_10_11_04_36_ cafetotalseriehist.xls $>$. Acesso em: 18 set. 2012.

DIAS, K.G. de L. Fontes e doses de fósforo para o cafeeiro: produtividade, dinâmica de nutrientes no solo e nutrição mineral de plantas. 2012. 90p. Dissertação (Mestrado) - Universidade Federal de Lavras, Lavras.

FERNANDES, L.A.; FURTINI NETO, A.E.; FONSECA, F.C.; VALE, F.R. do. Crescimento inicial, níveis críticos de fósforo e frações fosfatadas em espécies florestais. Pesquisa Agropecuária Brasileira, v.35, p.1191-1198, 2000. DOI: 10.1590/ S0100-204X2000000600016. 
GALLO, P.B.; RAIJ, B. van; QUAGGIO, J.A.; PEREIRA, L.C.E. Resposta de cafezais adensados à adubação NPK. Bragantia, v.58, p.341-351, 1999. DOI: 10.1590/S0006-87051999000200014.

GUERRA, A.F.; ROCHA, O.C.; RODRIGUES, G.C.; SANZONOWICZ, C. Manejo da irrigação do cafeeiro, com estresse hídrico controlado, para uniformização de florada. In.: ZAMBOLIM, L. (Ed.). Boas práticas agrícolas na produção de café. Viçosa: UFV, 2006. p.83-116.

GUERRA, A.F.; ROCHA, O.C.; RODRIGUES, G.C.; SANZONOWICZ, C.; RIBEIRO FILHO, G.C.; TOLEDO, P.M. dos R.; RIBEIRO, L.F. Sistema de produção de café irrigado: um novo enfoque. Irrigação e Tecnologia Moderna, n.73, p.52-61, 2007.

GUIMARÃES, P.T.G. Respostas do cafeeiro (Coffea arabica $\mathbf{L}$. cv. Catuaí) à adubação mineral e orgânica em solos de baixa fertilidade do sul de Minas Gerais. 1986. 140p. Tese (Doutorado) - Escola Superior de Agricultura Luiz de Queiroz, Piracicaba.

LAVIOLA, B.G.; MARTINEZ, E.M.P.; SALOMÃO, L.C.C.; CRUZ, C.D.; MENDONÇA, S.M.; PAULA NETO, A. Alocação de fotoassimilados em folhas e frutos de cafeeiro cultivado em duas altitudes. Pesquisa Agropecuária Brasileira, v.42, p.1521-1530, 2007a. DOI: 10.1590/S0100-204X2007001100002.

LAVIOLA, B.G.; MARTINEZ, E.M.P.; SOUZA, R.B. de; ALVAREZ V., V.H. Dinâmica de P e S em folhas, flores e frutos de cafeeiro arábico em três níveis de adubação. Bioscience Journal, v.23, p.29-40, $2007 b$.

LAVIOLA, B.G.; MARTINEZ, H.E.P.; SOUZA, R.B. de; SALOMAO, L.C.C.; CRUZ, C.D. Macronutrient accumulation in coffee fruits at Brazilian Zona da Mata conditions. Journal of Plant Nutrition, v.32, p.980-995, 2009. DOI: 10.1080/01904160902872164.

MALAVOLTA, E.; FAVARIN, J.L.; MALAVOLTA, M.; CABRAL, C.P.; HEINRICHS, R.; SILVEIRA, J.S.M. Repartição de nutrientes nos ramos, folhas e flores de cafeeiros. Pesquisa Agropecuária Brasileira, v.37, p.1017-1022, 2002. DOI: 10.1590/ S0100-204X2002000700016.

MALAVOLTA, E.; VITTI, G.C.; OLIVEIRA, S.A. de. Avaliação do estado nutricional das plantas: princípios e aplicações. 2.ed. Piracicaba: Potafos, 1997. 319p.

MARTINEZ, H.E.P.; NOVAIS, R.F.; RODRIGUES, L.A.; SACRAMENTO, L.V.S. Phosphate forms in plant and their internal buffering in five soybean cultivars. Revista Brasileira de Ciência do Solo, v.29, p.249-257, 2005. DOI: 10.1590/ S0100-06832005000200010.

MARTINEZ, H.E.P.; SOUZA, R.B.; ALVAREZ V., V.H.; MENEZES, J.F.S.; NEVES, Y.P.; OLIVEIRA, J.A.; ALVARENGA, A.P.; GUIMARÃES, P.T.G. Nutrição mineral, fertilidade do solo e produtividade do cafeeiro nas regiões de Patrocínio, Manhuaçu, Viçosa, São Sebastião do Paraíso e Guaxupé. Belo Horizonte: Epamig, 2004. 60p. (Epamig. Boletim técnico, 72).

MELO, B. de; MARCUZZO, K.V.; TEODORO, R.E.F.; CARVALHO, H. de P. Fontes e doses de fósforo no desenvolvimento e produção do cafeeiro, em um solo originalmente sob vegetação de cerrado de Patrocínio - MG. Ciência e Agrotecnologia, v.29, p.315-321, 2005. DOI: 10.1590/S1413-70542005000200007.

NOVAIS, R.F. de; SMYTH, T.J. Fósforo em solo e planta em condições tropicais. Viçosa: Ed. da UFV, 1999. 399p.

OSTERTAG, R. Foliar nitrogen and phosphorus accumulation responses after fertilization: an example from nutrient-limited Hawaiian forests. Plant and Soil, v.334, p.85-98, 2010. DOI: 10.1007/s11104-010-0281-X.

PREZOTTI, L.C.; ROCHA, A.C. da. Nutrição do cafeeiro arábica em função da densidade de plantas e da fertilização com NPK. Bragantia, v.63, p.239-251, 2004. DOI: 10.1590/ S0006-87052004000200009.

RAIJ, B. van; CANTARELLA, H.; QUAGGIO, J.A.; FURLANI, A.M.C. (Ed.). Recomendações de adubação e calagem para o estado de São Paulo. 2.ed. Campinas: Instituto Agronômico, 1997. 285p. (IAC. Boletim técnico, 100).

RAGHOTHAMA, K.G.; KARTHIKEYAN, A.S. Phosphate acquisition. Plant and Soil, v.274, p.37-49, 2005. DOI: 10.1007/ s11104-004-2005-6.

REIS, T.H.P.; GUIMARAES, P.T.G.; FURTINI NETO, A.E.; GUERRA, A.F.; CURI, N. Soil phosphorus dynamics and availability and irrigated coffee yield. Revista Brasileira de Ciência do Solo, v.35, p.503-512, 2011. DOI: 10.1590/ S0100-06832011000200019.

RIBEIRO, A.C.; GUIMARAES, P.T.G.; ALVAREZ V., V.H. (Ed.). Recomendação para o uso de corretivos e fertilizantes em Minas Gerais: $5^{\text {a }}$ aproximação. Viçosa: Comissão de Fertilidade de Solo do Estado de Minas Gerais, 1999. 359p.

ROUACHED, H.; ARPAT, A.B.; POIRIER, Y. Regulation of phosphate starvation responses in plants: signaling players and cross-talks. Molecular Plant, v.3, p.288-299, 2010. DOI: 10.1093/ $\mathrm{mp} / \mathrm{ssp} 120$.

SANTOS, J.Z.L.; RESENDE, A.V. de; FURTINI NETO, A.E.; CORTE, E.F. Crescimento, acúmulo de fósforo e frações fosfatadas em mudas de sete espécies arbóreas nativas. Revista Árvore, v.32, p.799-807, 2008. DOI: 10.1590/S0100-67622008000500003.

SILVA, L. da; MARCHIORI, P.E.R.; MACIEL, C.P.; MACHADO, E.C.; RIBEIRO, R.V. Fotossíntese, relações hídricas e crescimento de cafeeiros jovens em relação à disponibilidade de fósforo. Pesquisa Agropecuária Brasileira, v.45, p.965-972, 2010. DOI: 10.1590/S0100-204X2010000900005.

TAIZ, L.; ZEIGER, E. Fisiologia vegetal. 4.ed. Porto Alegre: Artmed, 2009. 819p.

VALARINI, V.; BATAGLIA, O.C.; FAZUOLI, L.C. Macronutrientes em folhas e frutos de cultivares de café arábica de porte baixo. Bragantia, v.64, p.661-672, 2005. DOI: 10.1590/ S0006-87052005000400016.

WANG, X.; SHEN, J.; LIAO, H. Acquisition or utilization, which is more critical for enhancing phosphorus efficiency in modern crops? Plant Science, v.179, p.302-306, 2010. DOI: 10.1016/j. plantsci.2010.06.007.

Recebido em 31 de outubro de 2012 e aprovado em 28 de junho de 2013

Pesq. agropec. bras., Brasília, v.48, n.7, p.765-773, jul. 2013 DOI: 10.1590/S0100-204X2013000700009 